\title{
Research on PE Teaching and Students' Ability Cultivation
}

\author{
Yong Liu \\ Department of Physical Education, Yulin University, Yulin, 719000
}

\author{
Keywords: PE Teaching, Student Ability Cultivation, Research Model
}

\begin{abstract}
The college students' physical condition is benefited from the physical education in colleges and universities, and the reform of college physical education is an important measure for the full implementation of quality education. Through the discussion on the reform of college physical education, the paper analyzes the relationship between the physical quality of college students and the reform of college physical education, arguing that physical quality is an important part of college students 'comprehensive quality, and physical education is irreplaceable in college students' comprehensive quality improvement teaching Function. Accelerating the reform of PE teaching mode has an important effect on cultivating the comprehensive quality of college students' health and creating compound talents..
\end{abstract}

\section{Introduction}

Healthy physique, good physical fitness is the material capital of college students to compete. The quality of college students includes the quality of political thought, scientific and cultural quality, psychological quality, physical quality, in which physical quality is the material basis for growth and talent. In the increasingly fierce competition for talent, the transformation of social mechanism, the conflict between old and new values, the collision of multi-dimensional ideological and cultural collision, the ideological impact of college students is inevitable, causing a lot of college students cognitive imbalance, psychological turmoil and ideological pressure The With the social requirements of the standards of talent is getting higher and higher, talent not only have the necessary professional skills, and its physical quality, psychological quality, ideological quality should pass the standard. Colleges and universities should play an important role in the development of students' physical quality. Therefore, in the current new period, colleges and universities should continue to adapt to the needs of the society, so as to improve the overall quality of college students as a teaching goal. Should be the trend from the physical education teaching guiding ideology, teaching mode, teaching methods, teaching evaluation and a series of reforms. In the establishment of "health first, life-long sports" concept, in accordance with the law of physical and mental development of college students, taking into account the characteristics of their own students and hobbies, to teach students to learn physical training methods to achieve mastery of training skills, enhance physical exercise ability, The purpose of physical fitness.

\section{Current Situation of College Physical Education and College Students' Physical Quality}

In the face of huge employment pressure, the majority of college students, "learning and gifted" concept is still deep-rooted, that only excellent results to lead everything, resulting in the quality of college physical and learning quality is not symmetrical. They are perennial in a busy state, the body was not the proper exercise. Even on the sports elective course, but also the lack of guidance on the choice, had to passively passive, as long as the credit can be achieved. On the other hand, the school, despite recognizing the importance of the physical quality of the students, has weakened the comprehensive and diversified research on the teaching level due to the influence of the traditional PE teaching model, and still repeats the emphasis on professional skills education Quality training "of the stereotypes. Most students are busy with English, computer, certified public accountants and 
other professional certificates, the body for a long time lack of healthy exercise, resulting in a single student knowledge, institutional weakness, myopia increased, malaise and other sub-health phenomenon. Liu Chengxiang, Liu Lin. In the analysis of the physical quality of college students that the impact of college students physical quality factors both objective and subjective, to explore the study can cause student interest in fitness form, content and methods and scientific management supervision is the current college students, sports Management and teaching departments need to solve the important issue.

Due to the influence of PE teaching model in the former Soviet Union, most of the physical education teaching models in our country are based on teachers. Check the peak that [3], the domestic influential physical education teaching model are used in the traditional teaching methods are based on "indoctrination" way to teach, are too much emphasis on the dominant position of teachers, ignoring the autonomy of students, resulting in Students can only passively study under the arrangement of instructors. Physical education is only focus on the improvement of physical fitness and the progress of technology and skills, the lack of training of sports awareness, students are always in the passive learning state, and now emphasizes the students as the main way of teaching contrary. The current situation of college physical education is that most colleges and universities in the first two years of college students to set up physical education courses, but the latter two years are reduced or no longer set up physical education courses, even if the set of two or two weekly sports courses can not achieve the physical and mental exercise of college students purpose. Moreover, the number of students in the face of increasing enrollment, and sports venues, facilities, equipment has changed little, unable to adapt and meet the needs of students to carry out physical fitness. As well as follow the years of physical education programs, teaching models and evaluation system, but also seriously constrain the modern sports teaching work carried out. All of which led to the college PE teaching objectives greatly reduced, resulting in college students physical quality worrying situation.

Nowadays college PE teaching generally practiced the credit system, college students can according to their own needs for different subjects or even different courses elective. College students in the specified time to complete the course and achieve learning points, to complete the physical education curriculum tasks. The advantage of physical education management is to enable students to learn autonomy, but at the same time exposed the weakness of school management loosely lagging behind. Through the relevant statistical survey can be seen, China's undergraduate education in physical education set, mainly freshman, sophomore, and junior, senior is no physical education courses. In particular, the four school year physical education curriculum arrangements, the former more than before, after the tight before the loose set, can not make college students to maintain the continuity of physical fitness, physical education in improving the overall quality of students in the role is not better The play, virtually weakened the college to improve the overall quality of the function of students.

\section{Problems in Current College Physical Education}

Although the reform of colleges and universities have been shouted for many years, although some colleges and universities have different degrees of different attempts to reform, but the reality of physical education model is still not broken, the majority of teachers are still confined to the traditional education ideas. First of all, in the teaching concept, there is no established lifelong sports thought, ignoring the inherent needs of students, there is a "body" and "education" on the human out of touch. Second, the school sports facilities "debt" too much. Some college sports facilities, poor level of hardware, and some colleges and universities software facilities is "more than a few"; some colleges and universities mixed with three stadiums, and some college teachers a serious shortage. All of these, can not open enough normal teaching courses, restricting the development of college physical education should be.

Classroom model, unified content, sports skills, which is the current prevalence of college physical education teaching situation. The reason why the traditional sports teaching model boring, mainly because of the formation of sports skills as the center, to exercise skills as a guide, and 
stressed the unity of common teaching methods. In reality, because of each college students' personality, physical fitness and hobby differences, doomed the irrationality of the method of physical education teaching, ignoring the comprehensive and diversified teaching level. In the teaching methods, emphasis on the theory of teaching, contempt for the practice of sports skills, teachers to explain the demonstration, light students ability to cultivate the phenomenon has not fundamentally changed. College students lack the opportunity to choose their own sports, have the opportunity and lack of space and equipment, this neglect of students specialty, ignoring the gender, personality and physical differences in teaching mode, has been unable to adapt to modern physical education. The era of physical education in colleges and universities issued an appeal: must be as soon as possible to eliminate the long-standing, the establishment of the operation can stimulate interest in learning, fitness skills, improve the physical quality of students of new sports teaching mechanism.

Talking about the evaluation mechanism of sports assessment, many college students out of the existing mechanism of evaluation. In short, some college students as long as the skills better, even if the lack of class, bad discipline can pass the examination. The sports foundation, poor physical skills students, no matter how serious study, can not test the good results, and cause this phenomenon is the assessment mechanism. Sports standards can not be separated from the assessment system, can not do without the establishment of physical fitness standards, but this attention to the process of neglecting the process of assessment mechanism, a bit out of practical teaching, it is difficult to stimulate students to practice sports requirements. Students are not professional athletes, this mechanism can not be too focused on assessing the level of athletic competition, one is not conducive to the physical and mental health of students, and secondly contrary to the principle of quality education, can not mobilize the enthusiasm of students to learn sports and initiative, To improve the physical quality of students to promote the comprehensive development of the original intention.

\section{Cultivation of Students' Lifelong Physical Ability and Habits in Physical Education}

School physical education should be a lifelong sports entry, become an important process of lifelong physical education, and students are the main body of this process. Therefore, teachers in physical education, first of all should strengthen the education of students' lifelong sports thought, clear the relationship between sports and health, establish the correct sports values, so that students fully aware of the function of sports, sports experience in the process to fully experience the sports Charm, to stimulate students interest in sports, so as to develop the habit of regular exercise. At the same time, to make students clear, adhere to the final body exercise, has been in the country, the people of great significance. In addition, in the teaching of physical education should also do a good job in the transformation of the concept of student sports, and implement the people-oriented, teaching and educating the purpose. It is necessary to pay attention to the teaching and teaching of the theory of sports theory, and to clarify the value and function of physical exercise for life in the course of sports theory. It is clear that lifelong sports is not only the need of personal survival, life, enjoyment and development, but also the needs of social development and progress. Students' awareness of these issues through education will improve their enthusiasm, interests and hobbies, and the idea of physical exercise for life will be stronger, so that they can lay the foundation for lifelong sports.

To be engaged in lifelong physical exercise, it is necessary to mobilize the students to exercise the body's consciousness and enthusiasm, and the initiative and enthusiasm of the motivation comes from the students of sports interest and hobbies, therefore, in physical education, teachers should be good at training students to sports Interest, must not be completed in order to complete the task of physical education, and pay no attention to the cultivation of student sports interest. In the past, due to the influence of the concept of physical education teaching, there is no shortage of compulsory teaching of physical education, the practice of suppressing the enthusiasm of students, ignoring the physical and psychological characteristics of students, and the practice of physical education and skills. , Students tend to feel tired, resulting in "body Shun and heart", the study of physical 
education students have a rebellious psychological practice on the negative emotions, to do so to enhance student physique, improve health and development of psychological quality are It is necessary to pay attention to cultivating students' interest in sports, and according to the age, physiological and psychological characteristics of the students, choose the content of the students' interest and the students' interest in sports. Method to carry out teaching, at the same time, but also to students the opportunity to practice the project, which is very useful for students to develop sports interest. At the same time, while emphasizing the cultivation of student sports interest, but also pay attention to students' creative learning and active learning, in physical education to establish the concept of active sports teaching, it is necessary to play the leading role of teachers to fully display the teacher's ability, and Should pay attention to play the main role of students, let the students themselves to practice, teachers should use the eyes of appreciation to see the success and failure of students, and more encourage less blame, warm guidance. In the teaching of physical education to respect and develop the personality of students, and pay attention to the development of students 'intelligence, so that students take the initiative, positive, consciously to experience the fun of learning sports, which is to develop students' lifelong sports ability and habits is of great benefit.

School sports as an important part of lifelong sports, requiring school physical education according to the school and students 2 aspects of reality, to play the advantages of centralized system learning for life-long physical lay a solid foundation. One of the keys to the ultimate realization of lifelong sports is that when the objective conditions are met, the degree of love of the students after leaving the school to the job, whether they have the habit of exercising the body, and the exercise of the body independently ability. To this end, the existing sports teaching materials system must be reformed. Among them, the teaching content should be based on the objectives of the course, highlighting the basic knowledge of sports content, increase the number of sports theory teaching hours. The theory of teaching materials should be selected to strengthen the students awareness of fitness, enhance fitness ability, the principle and methods of conservation of physical and mental aspects such as lifelong sports to enhance physical fitness, improve the role of the Chinese nation's health level, physical exercise principles and methods, Of the medical supervision. Practical teaching materials should break the competitive system as the center of the teaching system, select a high fitness value, students can benefit from the life of the project as a teaching material, so that the content of teaching materials flexible, diversified, and enhance the proportion of students to choose to adapt to life Sports needs.

\section{Conclusion}

In the reform of physical education, the first is the establishment of teaching philosophy, and then is the teaching methods and teaching content innovation. The key to physical education is to construct the integration mechanism of physical education teaching, training and competition, so as to achieve the common improvement of students' innovative thinking, innovation ability and physical quality. Reform the teaching model of physical education, to cultivate the comprehensive ability of students as the fundamental, closely linked to knowledge, ability, technology to teach this chain, so that teaching and practice closely linked to achieve the focus of teaching from the teacher to the main transfer of students, so as to achieve students Get the knowledge, improve the ability to exercise the body's goal, to achieve the combination of college physical education and students lifelong sports goals.

\section{Acknowledgements}

Yulin college professional talent training scheme reform research project in 2017(TJG1752) 


\section{References}

[1] motor. Sports elective course how to develop students to develop the habit of exercise [J]. Students (new concept of education). 2013 (05)

[2] Liu Yan. Development orientation and approach of college campus volleyball [J]. Journal of Chifeng University. 2013 (07)

[3] Yang Yongqiang. How to promote physical education in the training habits of students to develop [J]. New curriculum.) 2011 (06)

[4] Cui Ligen. "Sunshine Sports" under the background of college students physical exercise behavior analysis [J]. Public Commerce. 2010 (10)

[5] Ma Hongwei. Physical training habits of the research overview and prospects [J]. Teaching and management. 2009 (03)

[6] Wang Xiaohong. College physical education teaching students lifelong physical exercise habits [J].Journal of Inner Mongolia University of Finance and Economics 2007 (01) 